WANL-TME-695

February 21, 1964

\title{
INEFFICIENCY OF FILM BOILING HEAT TRANSFER AND EFFECT ON REACTOR START-UP
}

by

J. W. H. Chi

Fluid Flow Laboratory Experimental Engineering

This report was prepared as an account of work
sponsored by the United States Government. Nether
the United States nur the United States Atomic Energy
Commission, nor any of their employees, nor any of
their contractors, subcontractors, or their employees,
makes any warranty, express or implied, or assumes any
legal liability or responsibility for the accuracy, com-
pleteness or usefulness of any information, apparatus,
product or process disclosed, or represents that its use
would not infringe privately owned rights.

Approved By:

Brichtaur

R. N. Eichbauer, Supervisor WANHEF Facility

E. A. DeZubary, Manager

Fluid Flow Laboratory

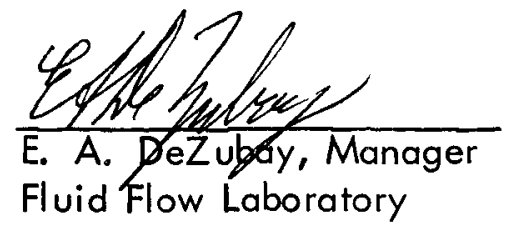

INFORMATION CATEGORY

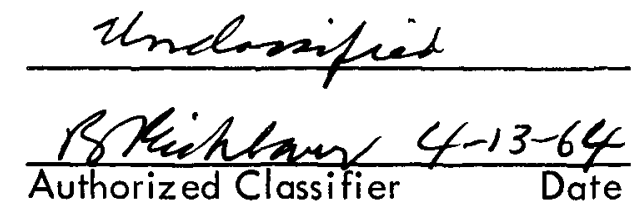




\section{DISCLAIMER}

This report was prepared as an account of work sponsored by an agency of the United States Government. Neither the United States Government nor any agency Thereof, nor any of their employees, makes any warranty, express or implied, or assumes any legal liability or responsibility for the accuracy, completeness, or usefulness of any information, apparatus, product, or process disclosed, or represents that its use would not infringe privately owned rights. Reference herein to any specific commercial product, process, or service by trade name, trademark, manufacturer, or otherwise does not necessarily constitute or imply its endorsement, recommendation, or favoring by the United States Government or any agency thereof. The views and opinions of authors expressed herein do not necessarily state or reflect those of the United States Government or any agency thereof. 


\section{DISCLAIMER}

Portions of this document may be illegible in electronic image products. Images are produced from the best available original document. 
From an experimental study on the cool-down of a copper tube by liquid hydrogen it was observed that in the film boiling regime, slug flow is the primary mechanism of twophase flow. Moreover, a super-heated vapor was found to exist simultaneously with the liquid at its boiling point. These facts suggest that only a fraction of the total heat transferred during film boiling becomes heat of vaporization.

Based on the experimental data, a two-step film boiling heat transfer mechanism is postulated:

1. Heat is transferred from the wall to the vapor, and then

2. Heat is transferred from the vapor to the liquid.

The ratio of the second step to the first is defined as the efficiency of film boiling.

Equations were derived and the efficiencies of film boiling were calculated from the experimental data. It was shown that the efficiency of film boiling heat transfer is indeed significantly less than one. The implication of this fact on reactor start-up can be inferred:

1. Choking two-phase flow in the nozzle coolant passages occurs for a longer period when compared to the assumption that $100 \%$ of the heat transferred becomes heat of vaporization.

2. Two-phase flow would appear in a greater part of the reactor, possibly penetrating the reflector.

3. As a consequence of Item 1, transient start-up may require a longer period.

A correlation was developed which permits the estimation of the local heat flux from the vapor to the liquid. The application of this correlation to transient, reactor start-up analys is is discussed. 


\section{INTRODUCTION}

Forced convection film boiling heat transfer has found very little application until the advent of nuclear rocket propulsion. Such a propulsion system requires the use of liquefied hydrogen as a coolant as well as the propellant. The existance of high temperatures at certain parts of the system which are in contact with liquid hydrogen causes film boiling to occur. Several experimental investigations on forced convective boiling heat transfer to hydrogen have been carried out in recent years $1,2,3,4$. These studies had the primary aim of studying the heat flux from the wall to the bulk fluid.

A research program was initiated at WANL to study reactor start-up by the cooldown of metal test sections by liquid hydrogen. In a previous report 5 , the data were analyzed, and a forced convective boiling heat transfer correlation was developed. The correlation permits the calculation of the local heat flux (from the wall to the bulk fluid) with a high degree of confidence.

Based on the bulk fluid temperature traces obtained, it was observed ${ }^{5}$ that in the film boiling regime, slug flow is the predominant mode of two-phase flow. Moreover, superheated vapors were found to exist simultaneously with the liquid slugs. These facts suggest that only a fraction of the total heat transferred becomes heat of vaporization. In order to carry out transient start-up calculations, the state of the fluid at every location must be accurately predicted as a function of time. It is evident that such predictions require a knowledge of not only the total heat flux (from the wall to the fluid), but also the fraction of heat transferred that becomes heat of vaporization.

In the absence of such information, it has been commonly assumed $6,7,8$ that all the heat transferred to the two-phase fluid becomes heat of vaporization. On this basis, cooldown wall temperatures have been calculated. A comparison with experimental results have shown large discrepancies 5 . In particular, the propagation of errors amplified the discrepancies to such an extent that the deviations between observed and calculated wall temperatures and fluid qualities increased rapidly with time and distance. 
It became apparent that in order to design coolant channels and to analyze reactor start-up, information on the efficiency of film boiling heat transfer is required. For this purpose, the data from the cool-down studies is analyzed in an attempt to determine quantitatively the efficiency of film boiling heat transfer and to develop a correlation with which the efficiency can be predicted. 


\section{THEORY OF FORCED CONVECTION FILM BOILING HEAT TRANSFER}

Two-Step Heat Transfer Mechanism

By definition, film boiling occurs when the heating surface becomes blanketed by a continuous film of vapor. If the object of boiling heat transfer is considered to be the vaporization of the liquid, then film boiling heat transfer occurs as a two-step mechanism:

1. Heat is transferred from the wall to the vapor: $\left(\frac{Q}{A}\right)_{w \rightarrow v}$

2. Heat is then transferred from the vapor to the liquid: $\left(\frac{Q}{A}\right)_{V \rightarrow L}$

The ratio of the second step to the first shall be defined as the efficiency of film boiling, i. e. ,

$$
\Psi=\frac{\left(\frac{Q}{A}\right)_{V \rightarrow L}}{\left|\frac{Q}{A}\right|_{W \rightarrow V}}
$$

where $A$ is based on the inside tube diameter.

\section{Derivation of Equations}

The complex fluid flow phenomena observed in film boiling preclude a detailed microscopic balance on the system; furthermore, the non-isothermal two-phase states suggest that in the final analysis, equations of continuity and energy may have to be written for each phase. In this treatment, only the heat transfer aspects are considered. This is permissible since the fluid properties do not change appreciably with small changes in pressure.

From an energy balance on the metal test section, it has been shown previously that the local instantaneous heat flux from the wall to the fluid can be given by the equation 


$$
\left(\frac{Q}{A}\right)_{w \rightarrow v}=-\rho C_{p} \gamma \frac{d T_{w}}{d t}
$$

A nomenclature is given in the Appendix. Assuming that heat transfer to the liquid is by the two-step mechanism discussed above and that kinetic energy changes are negligible, an energy balance on the vapor phase over a differential portion of the test section results in the equation

$$
\begin{aligned}
\left(\frac{Q}{A}\right)_{W \rightarrow v}-\left(\frac{Q}{A}\right)_{v \rightarrow L}-\frac{1}{\pi D_{i}}\left[\frac{\partial y W C\left(\bar{T}_{v}-T_{0}\right)}{\partial z}\right] \\
=\frac{S}{\pi D_{i}}\left[\frac{\partial C \rho \rho_{v} \epsilon\left(\bar{T}_{v}-T_{0}\right)}{\partial t}\right]
\end{aligned}
$$

A nomenclature and the derivation of this equation are given in the Appendix. The mass fraction vapor, $y$, is related to the void fraction (or volume fraction vapor) by the equation

$$
y=\frac{\epsilon \rho_{v}}{\epsilon \rho_{v}+(1-\epsilon) \rho_{L}}
$$

Equations $(2-4)$ provide a general description of the transient, non-isothermal heat transfer occurring during chill-down. The complexity of the equations precludes a closedform solution, but with proper initial and boundary values as well as the transport coefficients, the equations may be solved numerically. A solution of the equations will not be attempted here. Instead, the equations are used to evaluate the rate of heat transfer from the vapor to the liquid. If the mass flowrate is a constant, Equation (3) can be simplified. Writing the equation in terms of enthalpies and heat fluxes gives 


$$
\left.\mid \frac{Q}{A}\right)_{w \rightarrow v}-\left(\frac{Q}{A}\right)_{v \rightarrow L}-\frac{W}{\pi D_{i}}\left(\frac{\partial y h_{v}}{\partial z}\right)_{t}=\frac{S}{\pi D_{i}}\left(\frac{\partial H_{v}}{\partial t}\right)_{z}
$$

Over short time intervals, $\frac{\partial H_{v}}{\partial t}$ may be neglected, and the equation reduces to

$$
\frac{W}{\pi D_{i}} d\left(y h_{v}\right)=\left(\frac{Q}{A}\right)_{W \rightarrow v} d z-\left(\frac{Q}{A}\right)_{v \rightarrow L} d z
$$

Assuming constant average values of $\frac{Q}{A}$ across the test section, Equation (6) can be integrated from the inlet to the exit plane:

$$
W\left(y_{2} h_{v 2}-y_{1} h_{v 1}\right)=\left[\left[\frac{Q}{A}\right]_{W \rightarrow v}-\left[\left.\frac{Q}{A}\right|_{v \rightarrow L}\right] A\right.
$$

From which the instantaneous rate of heat transfer from the vapor to the liquid can be obtained:

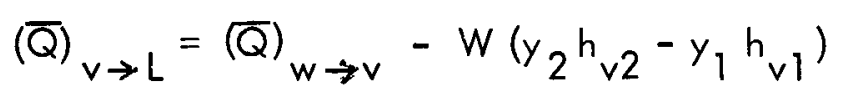




\section{ANALYSIS OF DATA}

The experimental data obtained from the cool-down of a 26-inch long copper test section were used in this analysis. The experimental equipment, test procedures, and instrumentation have been reported in detail elsewhere ${ }^{9}$.

\section{Average Efficiencies}

Average inlet and exit vapor temperatures and vapor fractions were determined by the method given in Reference 10. Local instantaneous wall to vapor heat fluxes were calculated from wall temperature histories and Equation (1). Arithmetic average wall to vapor heat transfer rates were used in Equation (9) to calculate the rate of heat transfer from the vapor to the liquid. Typical results on the average efficiencies are shown in Table I. It is evident from this Table that the efficiency of forced convection film boiling heat transfer increases with increasing chill-down, i. e., with decreasing fluid quality. This is expected from the apparent mechanism of film boiling heat transfer. It has been shown previously ${ }^{5}$ that fluid flow progresses from mist flow to slug flow and that the liquid slugs increase in length with increasing chill-down. It follows that the increased liquid slug lengths provide greater heat transfer surfaces, resulting in increased heat transfer from the vapor to the liquid.

Model of Film Boiling

In a previous report ${ }^{5}$, the mechanisms of two phase flow in the film boiling regime were discussed, and a slug flow model was postulated. Based on this model, a boiling heat transfer correlation was developed. Moreover, the same model had been used with success in the estimation of non-isothermal vapor fractions ${ }^{9}$. In view of these facts, it is evident that the heat transfer mechanism within the two-phase fluid must be consistent with the slug flow model. The inefficiency of film boiling can be directly attributed to the mechanism of slug flow. A schematic diagram of film boiling slug flow is shown below: 


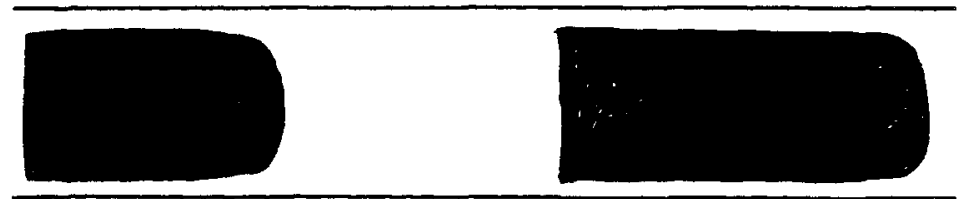

From the experimental data, the length of vapor slugs, i. e. , the distance between liquid slugs, can be estimated from the fluid velocity and vapor slug residence time:

$$
L_{v}=\theta_{v} v
$$

where $\delta_{v}$ is the vapor residence time, i. e. , the period that the thermocouple senses a superheated vapor temperature. Values of $L_{v}$ for a typical run are shown in Table II. From these results, the inefficiency of film boiling is manifest; the liquid slugs are so far apart that a greater part of the total heat transferred goes to superheat the vapor.

\section{Local Efficiencies}

The mechanism of slug flow suggests that the heat flux from the vapor to the liquid may be a function of $X_{T P^{\prime}}$ the fraction of the time liquid slugs flow past any location. Therefore, it is postulated that the local efficiency is directly proportional to the ratio of local $X_{T P}$ to average values, $\bar{X}_{T P^{\prime}}$. Hence

$$
\psi_{\text {local }}=\frac{x_{\text {TP }}}{\bar{x}_{T P}} \psi_{\text {average }}
$$

Linear average values, $\bar{X}_{T P}$, were calculated from the inlet and outlet values of $X_{T P}$, and the local efficiencies were calculated from Equation (9). 
The results are plotted versus $X_{T P}$ as shown in Figure 1 . It is apparent that there is some scatter in the data; however, a significant correlation is evident. Note that the efficiency decreases with decreasing $X_{T P}$. This is consistent with the mechanism of film boiling. For, as $X_{T P}$ decreases, the liquid content of the two-phase fluid decreases, and the liquid slugs or droplets (as in mist flow) become further apart. The result is that the amount of total heat transferred that becomes heat of vaporization decreases.

The correlation presented in Figure 1 shows that as $X_{T P}$ approaches $1, i, e_{0}$, annular flow, the efficiencyapproaches 1 , i. e. all the heat transferred becomes heat of vaporization. This implies that there is no net gain of energy in the vapor film. It is expected that vapor film thicknesses are small; therefore, a 100 percent efficiency for annular flow appears to be reasonable.

It has been shown in a previous report that local forced convective boiling heat flux for annular flow can be given by the equation

$$
\frac{Q}{A}=h_{f}\left(T_{w}-T_{f}\right)+\left|\frac{Q}{A}\right|_{B O}
$$

The fact that the efficiency approaches 100 percent as $X_{\text {TP }}$ approaches one suggests that for well developed slug flow, with relatively long liquid slugs, the heat flux from the vapor to the liquid may be approximated by the simple relationship

$$
\left|\frac{Q}{A}\right|_{V \rightarrow L}=X_{T P}\left[h_{f}\left(T_{w}-T_{f}\right)+\left(\left.\frac{Q}{A}\right|_{B o}\right]\right.
$$

The heat flux from the vapor to the liquid, calculated from Equation (11), is compared with the observed values in the following Table. 
FIGURE 1

EFFICIENCY OF FILM BOILING

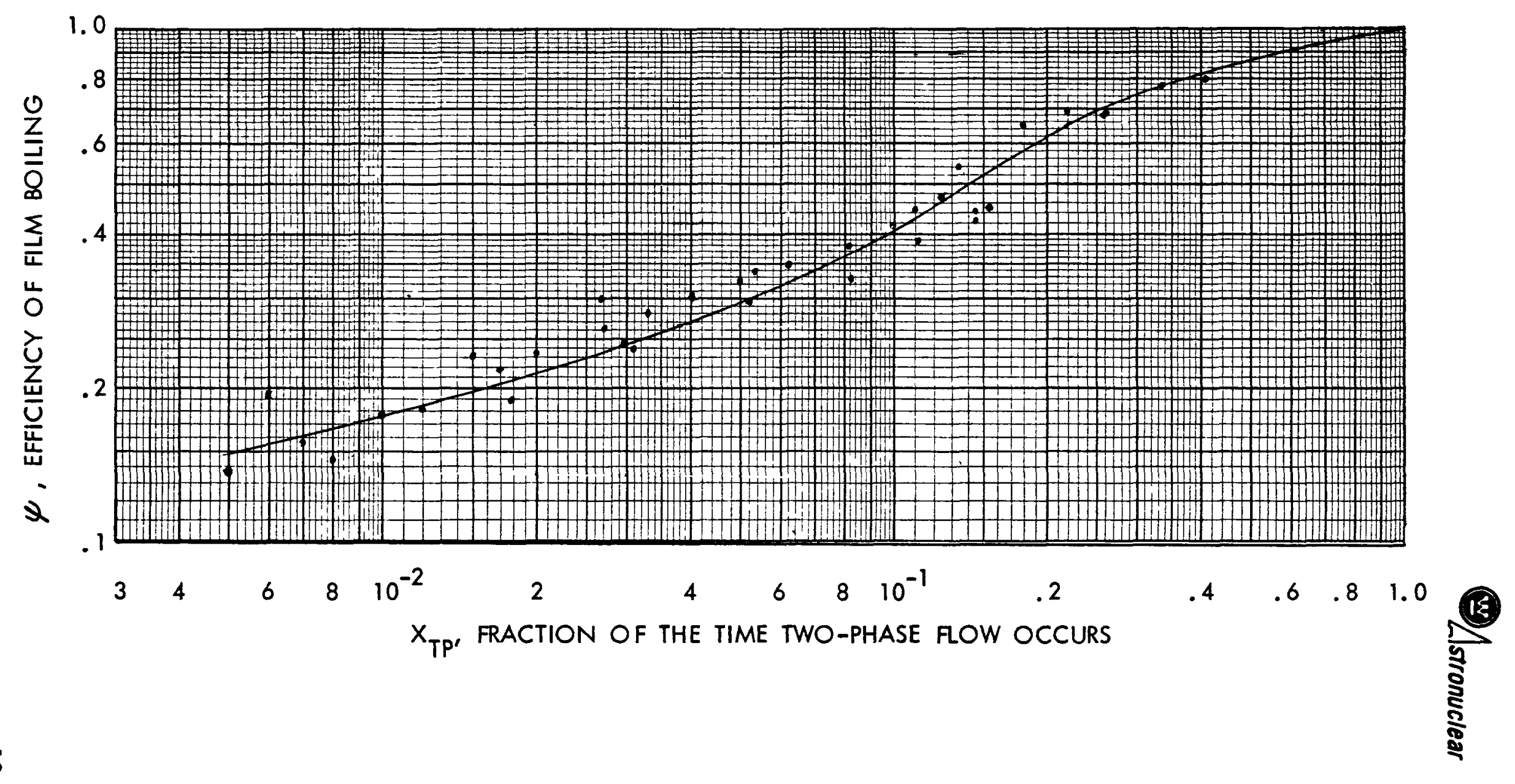


Cool-Down

Time, $t$

1

2

3

4

5

6

8

10
$\left|\frac{Q}{A}\right|_{V \rightarrow L}$

Observed

.028

.014

.008

.006

.004

.003

.003

.002
$\left|\frac{Q}{A}\right|_{V \rightarrow L}$

Calculated

.011

.010

.009

.008

.008

.008

.008

.007

It is evident from the Table that the calculated heat $\mathrm{flux}$ are of the same order of magnitude as those observed. However, the calculated values are initially lower than those observed, but with increased cool-down, the calculated heat flux becomes higher than those observed. These discrepancies can be attributed to the differences between the model and the actual mechanisms of two-phase flow.

At the initiation of chill-down, the fluid is primarily in mist flow with appreciable axial heat transfer. Since Equation (11) neglects axial heat transfer, the calculated heat flux is expected to be lower than the observed values. With increasing cool-down and increased liquid slug length, axial heat transfer at the ends of liquid slugs become negligible compared to radial heat transfer. However, part of the heat transferred to the vapor film may be lost as sensible heat, carried into vapor slugs by differences in phase velocities; consequently, the calculated heat flux would be higher than the actual values. This effect is negligible in mist flow, because the relative velocity of the two-phases is expected to be small in this case. 


\section{DISCUSSIONS AND CONCLUSIONS}

\section{Effect of Film Boiling on Reactor Start-Up}

It has been pointed out that in the absence of information on the efficiency of film boiling, cool-down and reactor start-up calculations 8 have generally been carried out by assuming that all the heat transferred become heat of vaporization. In view of the inefficiency of film boiling heat transfer, the consequences of such an assumption on reactor start-up analysis can be readily inferred:

1. Choking two-phase flow in the nozzle coolant passages occurs for a much longer period than predicted on the basis of the assumption.

2. Two-phase flow would exist in a greater part of the reactor than that indicated by the assumption, and

3. Transient start-up may require a longer period than that predicted by the assumption of $100 \%$ efficiency.

It should be pointed out that the experimental study on cool-down was carried out at extremely low flowrates, simulating approximately the first ten seconds of reactor startup. It has been shown in a previous report ${ }^{5}$ that the fraction of the time two-phase flow occurs $\left(X_{T P}\right)$ is directly proportional to the flowrate. Hence with increasing flowrate, $X_{\text {TP }}$ approaches one, i. e., annular flow with a liquid core. Extrapolation of the efficiency curve suggests that the efficiency approaches one with annular flow. In the absence of data at higher flowrates, this can not be verified.

In view of the indirect method by which the efficiencies were calculated, it is doubtful that the correlation proposed here can be used to predict reactor start-up with a high degree of accuracy. Nevertheless, use of the correlation will improve transient startup analysis and predict more realistic temperatures and fluid states. The appreciable effects that the efficiency of heat transfer have on transient calculations suggest that more accurate experimental data on the efficiencies are required if improved predictions on transient reactor start-up are desired. 


\section{REFERENCES}

1. Wright, C. C. and Walters, H. H., "Single Tube Heat Transfer Tests - Gaseous and Liquid Hydrogen", WADC-TR-59-423, August, 1959.

2. Core, T. C., Harkee, J. F., Misra, B., and Sato, K., "Heat Transfer Studies", WADD60-239, September, 1959.

3. Hendricks, R. C. , Graham, R. W. , Hsu, Y. Y., and Friedman, R., "Experimental Heat Transfer and Pressure Drop of Liquid Hydrogen Flowing Through a Heated Tube", NASA-TN-D-765, 1962.

4. Straight, D. M. , "Heat Transfer and Flow Data with Cryogenic Hydrogen for Nuclear Rocket System Design", Paper presented at the ASHRACE Cryogenic Symposium, New York, February 11, 1963.

5. Chi, J.W.H. , "Forced Convection Boiling Heat Transfer to Hydrogen", WANL-TNR154, March, 1964.

6. Steward, W. G. , et. al., "Research on Cooldown of Cryogenic Transfer Lines", Cryogenic Engineering Laboratory, National Bureau of Standards, Boulder, Colorado, October 1, 1962.

7. Thurston, R. S., "Effect of Two-Phase Flow in Start-Up of KIWI-B", Los Alamos Scientific Laboratory, Report 2803, March 15, 1963.

8. "Two-Phase Heat Transfer", WANL-TMI-751, July 24, 1963.

9. "Transient Two-Phase Heat Transfer and Flow Characteristics of Liquid Hydrogen", WANL-TNR-102, April, 1963.

10. Chi, J.W.H., and Vetere, A. M. , "Two-Phase Flow During Transient Boiling of Hydrogen and Determination of Non-Equilibrium Vapor Fractions", to be published in Advances in Cryogenic Engineering, Volume 9, 1964. 


\section{NOMENCLATURE}
A $=$ heat transfer area, in ${ }^{2}$
= heat capacity, BTU// $b-{ }^{\circ} \mathrm{R}$
D
$=$ diameter, in.
$=$ mass velocity, $\mathrm{l} b / \mathrm{in}^{2}-\mathrm{sec}$
h
= specific enthalpy, BTU/lb
$h_{f}$
$=$ heat transfer coefficient, BTU/in ${ }^{2}-\mathrm{sec}-{ }^{\circ} R$
= total enthalpy, BTU
k
$=$ thermal conductivity, BTU/in-sec- ${ }^{\circ} R$
L
= length of conduction path, in.
$N_{\operatorname{Re}}$
$=$ Reynolds Number, $D G / \mu_{f}$
$Q$
$=$ rate of heat transfer, $\mathrm{BTU} / \mathrm{sec}$
$\frac{Q}{A}$
$=$ local heat flux, BTU/in ${ }^{2}$-sec
$=$ cross sectional area of flow passage, in ${ }^{2}$
= time, second
$=$ temperature, ${ }^{{ }^{O}} \mathrm{R}$
$=$ mass flowrate, $\mathrm{lb} / \mathrm{sec}$
= fraction of the time liquid slugs flow past any point
$=$ mass fraction vapor, dimensionless
$=$ distance from the inlet of the test section
$=$ geometrical constant, $D_{0}^{2}-D_{i}^{2} / 4 D_{i}$, in
= slug residence time, sec.
= volume fraction vapor
$\mu$
$=$ viscosity, $\mathrm{lb} / \mathrm{in}-\mathrm{sec}$
p $\quad=$ density, $\mathrm{lb} / \mathrm{in}^{3}$
= efficiency of film boiling heat transfer 


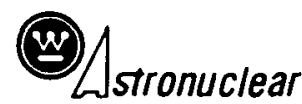

WANL-TME-695

$\begin{array}{ll}\text { Subscripts } & \\ \mathrm{f} & =\text { film } \\ \mathrm{i} & =\text { inside } \\ \mathrm{L} & =\text { liquid } \\ \mathrm{O} & =\text { outside or reference } \\ \mathrm{TP} & =\text { two-phase } \\ \mathrm{V} & =\text { vapor } \\ \mathrm{W} & =\text { wall }\end{array}$




\section{DERIVATION OF ENERGY EQUATION FOR THE VAPOR PHASE}

Consider a differential length of the test section, $\mathrm{dz}$. Let the two-phase fluid entering and leaving this section have a constant mass flow rate of $w$ pounds per second. The mass fraction vapor is $y$; hence the mass of vapor entering is $y w \mathrm{lb} / \mathrm{sec}$. Let $C$ be the average specific heat of the vapor. Then, assuming that kinetic energy changes are negligible, an energy balance on the vapor phase can be made over $\mathrm{dz}$. A schematic diagram is shown below:

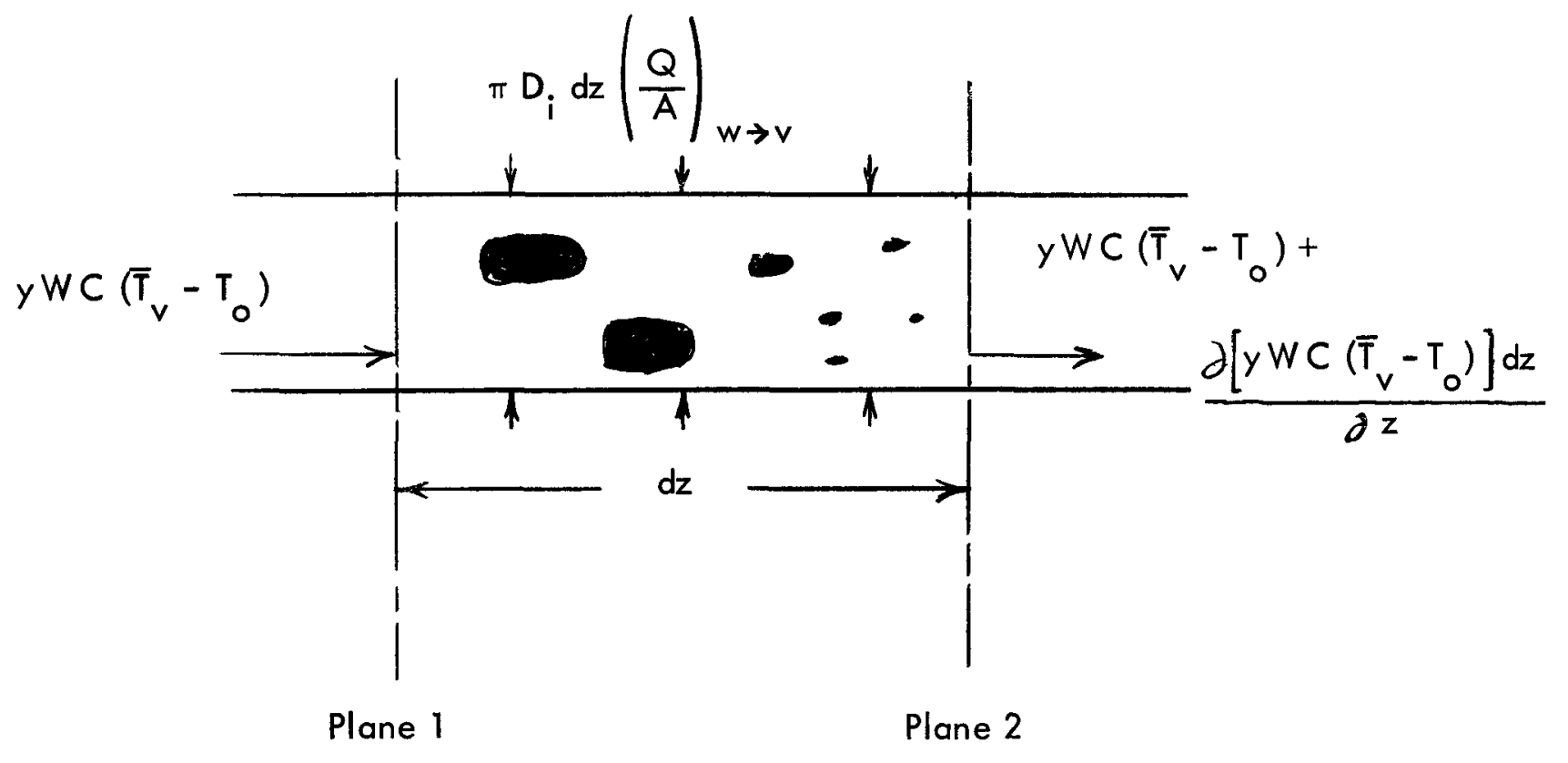

Energy in:

$$
y W C\left(\bar{T}_{v}-T_{0}\right)+\pi D_{i} d z\left|\frac{Q}{A}\right|_{w \rightarrow v}
$$


Energy out:

$$
-\pi D_{i} d z\left(\frac{Q}{A}\right)_{v \rightarrow L}-\left[y W C\left(T_{v}-T_{0}\right)+\frac{\partial\left[y W C\left(\bar{T}_{v}-T_{0}\right)\right]}{\partial z} d z\right]
$$

Energy accumulation:

$$
\frac{\partial\left[s d z \in \rho_{v} c\left(T_{v}-T_{0}\right)\right]}{\partial t}
$$

From which

$$
\left|\frac{Q}{A}\right|_{W \rightarrow v}-\left(\frac{Q}{A}\right)_{v \rightarrow L}-\frac{1}{\pi D_{i}} \frac{\partial\left[y W C\left(\bar{T}_{v}-T_{0}\right)\right]}{\partial z}=\frac{s}{\pi D_{i}} \frac{\partial\left[C \rho_{v} \in\left(\bar{T}_{v}-T_{0}\right)\right]}{\partial t}
$$




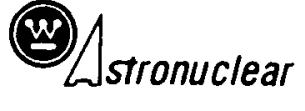

WANL-TME-695

\section{TABLE I}

COMPARISON OF LOCAL HEAT FLUXES IN TWO-STEP FILM BOILING HEAT TRANSFER (INLET OF TEST SECTION)

\begin{tabular}{r} 
Coo \\
Tim \\
secon \\
\hline \\
\\
1 \\
2 \\
3 \\
4 \\
5 \\
6 \\
8 \\
10 \\
12 \\
14 \\
16
\end{tabular}
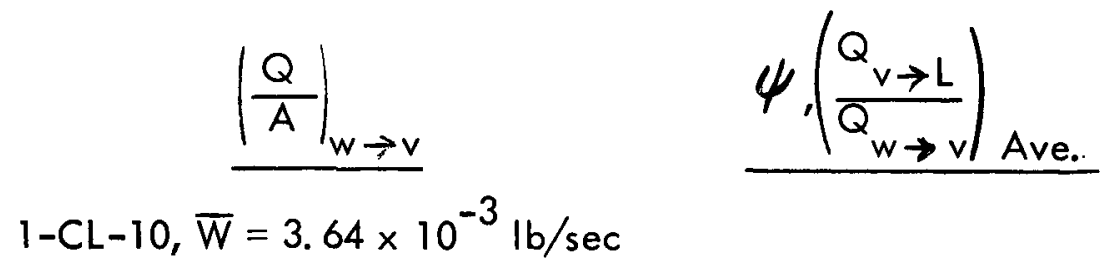

Cool-Down

Time

seconds

$$
1-\mathrm{CL}-10, \bar{W}=3.64 \times 10^{-3} \mathrm{lb} / \mathrm{sec}
$$

1

2

3

4

5

6

8

10

12

14

16

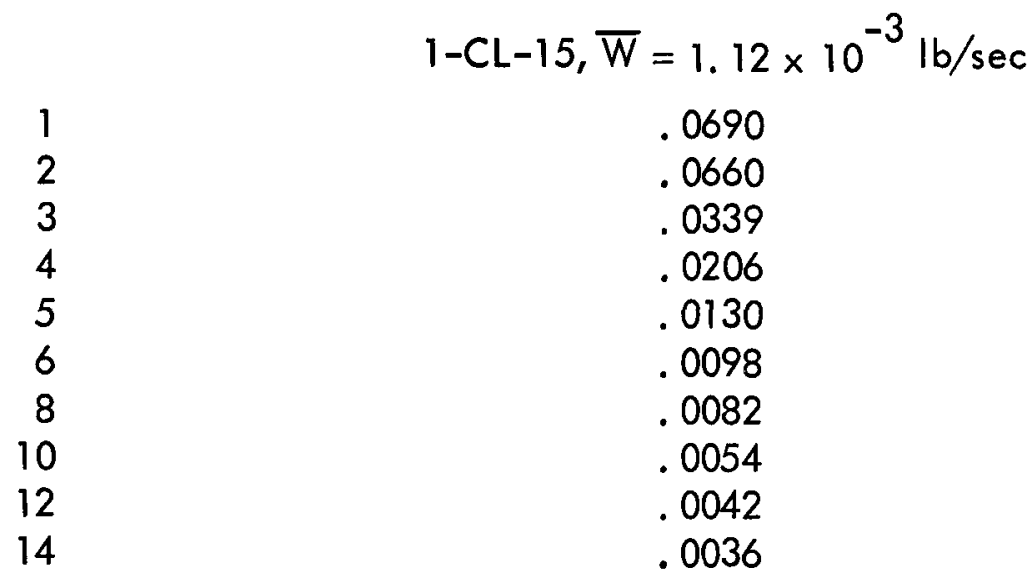

.1450

.0777

.0363

.0183

.0109

.0087

.0045

.0027

.0017

.0010

.0005

.0907

.1128

.1548

.2115

.2330

.2267

.3565

.4444

.5000

.5667

.6000

$\begin{array}{cc}1-\mathrm{CL}-15, \overline{\mathrm{W}} & =1.12 \times 10^{-3} \mathrm{Ib} / \mathrm{sec} \\ .0690 & .0822 \\ .0660 & .1015 \\ .0339 & .1058 \\ .0206 & .1085 \\ .0130 & .1231 \\ .0098 & .1429 \\ .0082 & .1830 \\ .0054 & .2113 \\ .0042 & .2000 \\ .0036 & .2651\end{array}$




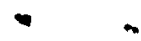

-

Lstronuclear

WANL-TME-695

TABLE \|

VAPOR SLUG LENGTHS DURING COOL-DOWN

$$
\sqrt{w}=3 \times 10^{-3} \text { LB/SEC) }
$$

\begin{tabular}{c} 
Cool-Down \\
Time, sec. \\
\hline 2 \\
3 \\
4 \\
5 \\
6 \\
8 \\
10 \\
12 \\
14 \\
16
\end{tabular}

\begin{tabular}{c} 
Local Average \\
Velocity, ft/sec \\
\hline 114 \\
76 \\
55 \\
40 \\
30 \\
22 \\
17 \\
17 \\
15 \\
15
\end{tabular}

Average

Vapor Residence Vapor Slug

Time, sec.

.90

.60

.50

.40

.30

.25

.22

.18

.15

.12
Length, ft.

103

45

27

16

9

5.5

3.7

3. 0

2. 2

1.8 